\title{
Caesarean section is associated with an increased risk of childhood-onset type 1 diabetes mellitus: a meta-analysis of observational studies
}

\author{
C. R. Cardwell • L. C. Stene • G. Joner • O. Cinek • \\ J. Svensson • M. J. Goldacre • R. C. Parslow • \\ P. Pozzilli • G. Brigis • D. Stoyanov • B. Urbonaitè • \\ S. Šipetić • E. Schober • C. Ionescu-Tirgoviste • \\ G. Devoti • C. E. de Beaufort • K. Buschard • \\ C. C. Patterson
}

Received: 5 November 2007 / Accepted: 14 January 2008/Published online: 22 February 2008

(C) Springer-Verlag 2008

\begin{abstract}
Aims/hypothesis The aim of this study was to investigate the evidence of an increased risk of childhood-onset type 1 diabetes in children born by Caesarean section by systematically reviewing the published literature and performing a
\end{abstract}

C. R. Cardwell $(\bowtie) \cdot$ C. C. Patterson

Department of Epidemiology and Public Health,

School of Medicine and Dentistry, Queen's University Belfast,

Grosvenor Road,

Belfast BT12 6BJ, UK

e-mail: c.cardwell@qub.ac.uk

L. C. Stene

Division of Epidemiology, Norwegian Institute of Public Health, Oslo, Norway

L. C. Stene $\cdot$ G. Joner

Diabetes Research Centre, Aker and Ullevål University Hospitals,

Oslo, Norway

G. Joner

Faculty of Medicine, University of Oslo,

Oslo, Norway

O. Cinek

Second Medical School, Charles University,

Prague, Czech Republic

J. Svensson

Steno Diabetes Centre,

Gentofte, Denmark

M. J. Goldacre

Department of Public Health, Oxford University,

Oxford, UK meta-analysis with adjustment for recognised confounders. Methods After MEDLINE, Web of Science and EMBASE searches, crude ORs and $95 \%$ CIs for type 1 diabetes in children born by Caesarean section were calculated from the data reported in each study. Authors were contacted to

\footnotetext{
R. C. Parslow

Paediatric Epidemiology Group, University of Leeds,

Leeds, UK

P. Pozzilli

University Campus Bio-Medico,

Rome, Italy

G. Brigis

Department of Public Health and Epidemiology,

Riga Stradins University,

Riga, Latvia

D. Stoyanov

Children's Diabetic Centre,

Sofia, Bulgaria

B. Urbonaite

Institute of Endocrinology, Kaunas University of Medicine,

Kaunas, Lithuania

S. Šipetić

Institute of Epidemiology, School of Medicine,

Belgrade University,

Belgrade, Serbia

E. Schober

Department of Paediatrics, Medical University of Vienna,

Vienna, Austria
} 
facilitate adjustments for potential confounders, either by supplying raw data or calculating adjusted estimates. Metaanalysis techniques were then used to derive combined ORs and to investigate heterogeneity between studies.

Results Twenty studies were identified. Overall, there was a significant increase in the risk of type 1 diabetes in children born by Caesarean section (OR 1.23, 95\% CI 1.15-1.32, $p<0.001)$. There was little evidence of heterogeneity between studies $(p=0.54)$. Seventeen authors provided raw data or adjusted estimates to facilitate adjustments for potential confounders. In these studies, there was evidence of an increase in diabetes risk with greater birthweight, shorter gestation and greater maternal age. The increased risk of type 1 diabetes after Caesarean section was little altered after adjustment for gestational age, birth weight, maternal age, birth order, breast-feeding and maternal diabetes (adjusted OR $1.19,95 \%$ CI $1.04-1.36, p=0.01$ )

Conclusions/interpretation This analysis demonstrates a $20 \%$ increase in the risk of childhood-onset type 1 diabetes after Caesarean section delivery that cannot be explained by known confounders.

Keywords Caesarean section - Cesarean section ·

Diabetes mellitus $\cdot$ Epidemiology $\cdot$ Type 1

\section{Introduction}

Although type 1 diabetes has an important genetic component [1], the marked increases in incidence rate observed among the under 15 age group in recent decades [2, 3] strongly suggest the role of environmental influences. Various observations have lead to speculation that Caesarean section delivery could be involved. Rapid increases in Caesarean section rates [4] have occurred in parallel with increasing diabetes rates. For example, rates of Caesarean

C. Ionescu-Tirgoviste

Nutrition and Metabolic Diseases Clinic,

'N. Paulescu' Institute of Diabetes,

Bucharest, Romania

G. Devoti

Department of Social Sciences and Communication, University of Lecce,

Lecce, Italy

C. E. de Beaufort

Clinique Pédiatrique Luxembourg,

Luxembourg, Luxembourg

K. Buschard

Bartholin Institutett,

Rigshospitalet,

Copenhagen, Denmark section in England, Sweden and the USA have risen from $6 \%, 8 \%$ and $10 \%$ in 1975 [5] to $19 \%, 12 \%$ and $22 \%$ in 1999 [4], respectively. Animal models suggest a higher risk of diabetes after Caesarean section [6, 7]. Also, children delivered by Caesarean section have been shown to have altered gut microbiotic composition and immune function [8-11], which could increase their risk of type 1 diabetes. Numerous studies have investigated Caesarean section and type 1 diabetes, but findings have been inconsistent, possibly as a result of inadequate size and limited power in some studies. In such a situation, meta-analysis is valuable in synthesising the available evidence [12].

The first aim of this study was to assess the evidence of an association between type 1 diabetes and Caesarean section by performing a meta-analysis. Previous studies have shown that various perinatal and early life factors are associated with type 1 diabetes, such as maternal age, birthweight and breastfeeding [13-15]. As such factors may differ in children born by Caesarean section, the second aim was to adjust the pooled estimate of the association between Caesarean section and type 1 diabetes for the influence of these potential confounders.

\section{Methods}

Literature search The main literature search was conducted using MEDLINE, through OVID ONLINE, with the following strategy: ('Cesarean Section' or 'Delivery, Obstetric' or cesarean or caesarean or mode of delivery) and ('Diabetes Mellitus, Type 1' or (diabetes and Type 1) or IDDM), using the terms in inverted commas as MEDLINE subject heading key words. Similar searches were conducted on Web of Science and EMBASE. To identify studies that investigated Caesarean section along with other risk factors, a more general search was conducted on MEDLINE using: ('Diabetes Mellitus, Type 1' and ('Case-Control Studies' or 'Cohort Studies')). The searches were limited to studies on humans, published before September 2007. Abstracts were screened independently by two investigators (C. R. Cardwell and C. C. Patterson) to establish if the studies were likely to provide relevant data based on the following inclusion criteria: (1) they identified a group with type 1 diabetes (containing more than 15 cases) and a group without type 1 diabetes, and (2) they determined the prevalence of delivery by Caesarean section in these groups. Citations generated from the more general MEDLINE search were initially screened to remove obviously irrelevant articles. Finally, the reference lists of all pertinent articles were examined.

Eligible studies were assessed independently by two reviewers (C. R. Cardwell and C. C. Patterson) to abstract information about the study (country, design and year of publication), participants with type 1 diabetes (source, age at 
onset), control participants (source) and mode of delivery (methods of ascertainment).

Attempts were made to contact the corresponding author of all eligible studies to facilitate adjustment for maternal age, birthweight, gestational age, birth order, breast-feeding and maternal diabetes. Authors were requested to provide raw data or to provide adjusted estimates of the association between Caesarean section and type 1 diabetes after conducting specified additional analyses.

Statistical analysis ORs and SEs were calculated for the association between diabetes and Caesarean section for each study. Conditional logistic regression was used to calculate the ORs and SEs for the matched case-control studies. In cohort studies with varying duration of participant followup, rate ratios and their SEs were used instead of ORs, which were not directly calculable. As type 1 diabetes is a rare disease, these measures should be approximately equal [16]. Poisson regression was used to adjust these rate ratios for differences in the year of birth between cases and controls, a consequence of this study design [17, 18], by adding a year of birth and age term to the regression model in addition to Caesarean section. Tests for heterogeneity between studies were conducted, and random effects models used to calculate pooled ORs [19]. Random effects models were deemed more appropriate than fixed effects models because it was anticipated that there would be between study heterogeneity due to their observational nature. The $I^{2}$ statistic was calculated to quantify the degree of heterogeneity between studies [20]. This statistic measures the percentage of the total variation across studies that is due to heterogeneity. Study-specific weights in the random effects model were calculated and scaled to percentages. Publication/selection bias was investigated by checking for asymmetry in funnel plots of the study ORs against the SE of the logarithm of the ORs [21]. In the absence of publication/selection bias this graph should conform to a funnel shape, as the OR estimates from smaller studies (with larger SEs) show greater variation around the overall estimate than the OR estimates from larger studies (with smaller SEs). An identical approach was adopted to combine ORs for the association between type 1 diabetes and available confounders. To investigate the trend across categories for maternal age and birthweight, an OR (and SE) was calculated per increase in category using regression models appropriate to the design of the study, and then meta-analysis techniques were applied.

A two-stage technique was used to calculate pooled estimates of the association between Caesarean section and diabetes after adjustment for potential confounders [22]. First, adjusted estimates and SEs were calculated within each study using regression models appropriate to the study design (logistic regression for case-control studies, conditional logistic regression for matched case-control studies and Poisson regression for cohort studies) including diabetes as the outcome variable and Caesarean section and the potential confounder(s) of interest as explanatory variables. As explained previously, Poisson regression models additionally included terms to adjust for differences in year of birth between cases and controls in the cohort studies with varying participant follow-up. Meta-analysis techniques were then applied to these adjusted estimates.

Sensitivity analyses were conducted by subdividing studies by quality (whether population-based randomly selected controls were used) and using the Trim and Fill method to calculate pooled estimates after adjustment for any potential publication bias [23]. This method identifies funnel plot asymmetry and imputes study results, which are considered to have been conducted but not published, to create funnel plot symmetry. The overall combined estimate of the association is then based on the observed and imputed study results.

All statistical analyses were performed using STATA 9.0 software (STATA, College Station, TX, USA).

\section{Results}

The searches identified nine eligible articles using MEDLINE $[15,17,24-30]$; a further article was identified from Web of Science [31] and another from EMBASE [32]. The more general MEDLINE search identified a further eight articles [33-40], and review of reference lists revealed another two articles [41, 42].

Seven of the identified articles were excluded from further consideration. An earlier study [41] was excluded in favour of a larger study [42] that included all the participants enrolled in the former. Three articles $[25,26,28]$ reported the same data. A study [33] was excluded because no raw data were presented in the paper or available from the authors. Another study was excluded as it contained fewer than 15 cases [29]. A meeting abstract [31] was replaced with the subsequently published article [43] and, after contact with authors, an earlier report from a cohort [35] was replaced with a later report [18].

The 16 remaining articles corresponded to 20 independent studies, because one study [15] provided data from eight centres, three of which were reported elsewhere [25, 27, 32], and another provided data from two centres [24], one of which was subsequently reported in a larger study [32]. Finally, to ensure two studies $[17,30]$ provided independent information, authors removed cases from one study [30] that were included in the other [17]. Study characteristics are summarised in Table 1.

The unadjusted association between Caesarean section and childhood-onset type 1 diabetes for all 20 studies, including 9,938 cases, is shown in Fig. 1. Overall, there was a significant increase $(p<0.001)$ in the risk of type 1 


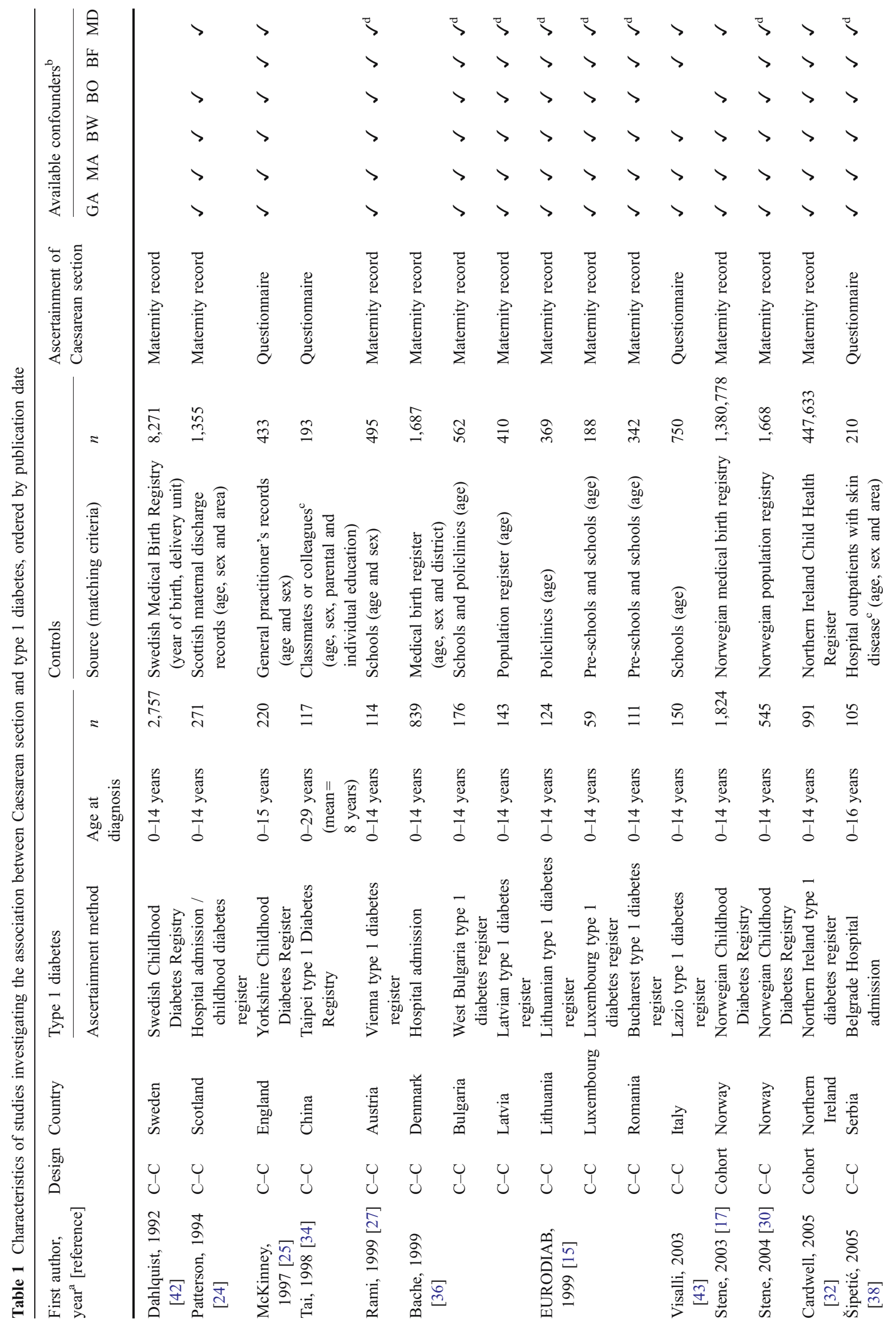




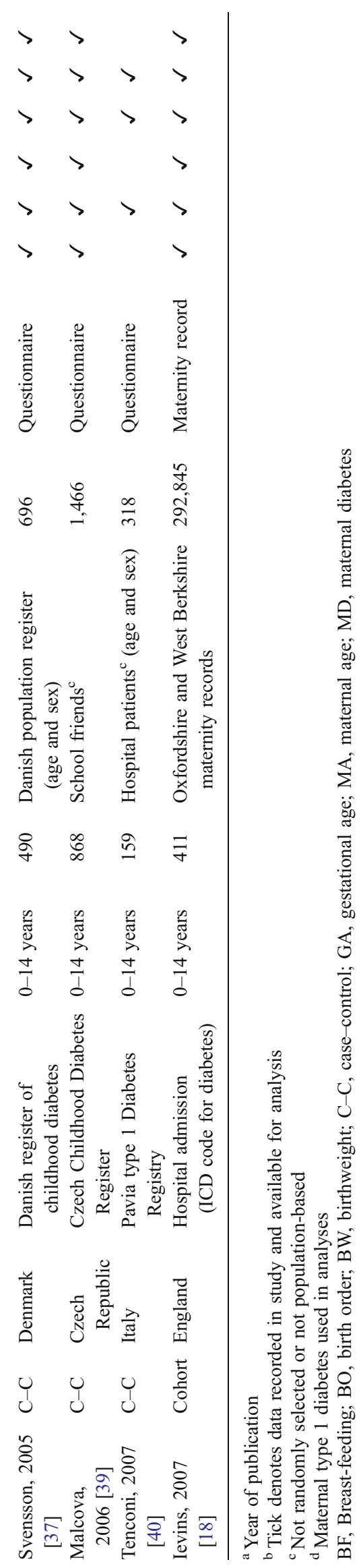




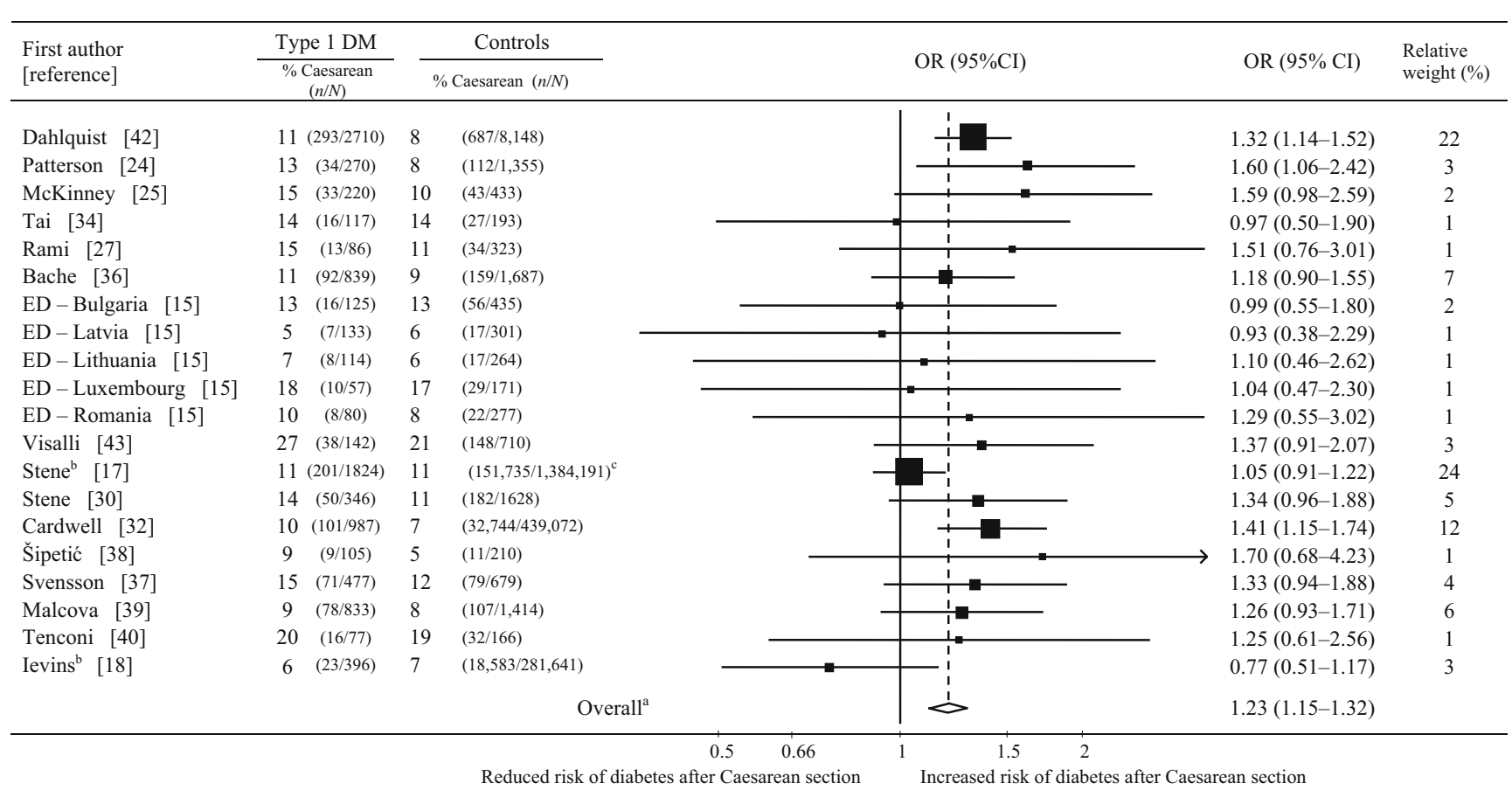

Fig. 1 Meta-analysis of studies of Caesarean section and type 1 diabetes (including 9,938 cases) using the random effects model, studies ordered by publication date. Reference numbers are provided in Table 1. ${ }^{\mathrm{a}}$ Test for heterogeneity $\chi^{2}=17.70, d f 19, p=0.54 ; I^{2}=0 \%$
(95\% CI $0-48 \%$ ); test for overall effect $Z=5.70, p \leq 0.001$; ${ }^{b}$ adjusted for year of birth and age group, as explained in Statistical analysis; ${ }^{c}$ approximated from person years. DM, diabetes mellitus; ED, EURODIAB diabetes after Caesarean section delivery, with an OR of 1.23 (95\% CI 1.15-1.32). There was little evidence of heterogeneity between the study estimates $\left(I^{2}=0 \%, 95 \%\right.$ CI $\left.0-48 \% ; \chi^{2}=17.70, d f 19, p=0.54\right)$. A funnel plot, shown in Fig. 2, roughly conformed to the expected funnel shape, providing little evidence of asymmetry and therefore little evidence of publication bias. Similarly, the Trim and Fill method, which attempts to adjust for any publication bias by imputing possible unpublished studies, produced estimates that were unaltered (OR 1.23), suggesting that any effect of publication bias was negligible. Further analysis in the subgroup of 16 studies judged to have used randomly

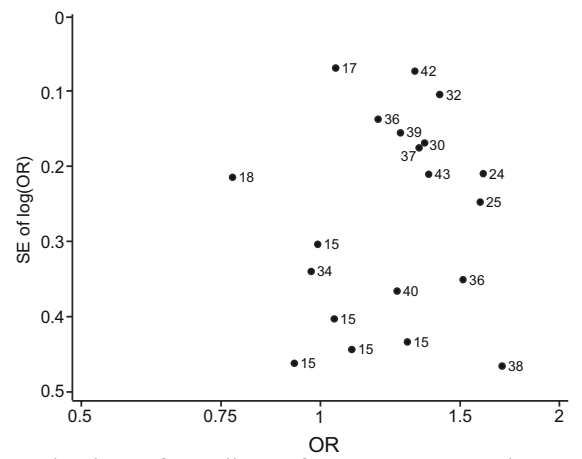

Fig. 2 Funnel plot of studies of Caesarean section and type 1 diabetes, labelled by reference number selected population-based controls produced a similar pooled estimate (OR 1.24, 95\% CI 1.13-1.35).

Adjustment for potential confounders was possible in 17 studies. Fifteen authors provided raw data, and two calculated adjusted estimates. Raw data from two studies were not available [36, 42] and one author could not be contacted [34].

Table 2 summarises the crude association between childhood-onset type 1 diabetes and potential confounders. Overall, there was an increase in the risk of diabetes with increasing birthweight (combined OR per category increase $1.05, p=0.006)$ and little heterogeneity between studies $\left(I^{2}=\right.$ $25, p=0.17)$. There was evidence $(p=0.02)$ of a reduction in risk of diabetes with longer gestation. The pooled risk of diabetes in children born later than 42 weeks was 0.84 times that of children born 38-41 weeks, and was similar across studies $\left(I^{2}=10, p=0.34\right)$. There was evidence of an increase in diabetes risk with maternal age (combined OR per category increase $1.08, p=0.001$ ) but there was considerable heterogeneity between studies $\left(I^{2}=50, p=0.01\right)$. Overall, there was some evidence that children second born (OR $1.12, p=0.03$ ) or third or later born (OR 1.08, $p=0.17$ ) had a slightly higher risk of type 1 diabetes than first born children, but these associations were also subject to considerable heterogeneity $\left(I^{2}=45, p=0.03\right.$ and $I^{2}=25, p=0.17$, respectively). Children whose mother had diabetes (OR 4.92, $p<0.001$ ) or, specifically, type 1 diabetes (OR $4.03, p=0.001$ ) had a higher risk of type 1 diabetes, and these associations 
were fairly consistent across studies $\left(I^{2}=0, p=0.49\right.$ and $I^{2}=0, p=0.88$, respectively). Finally, there was some indication that children who were breastfed, or breastfed for a longer duration, had a slightly lower risk of diabetes than children who were not breastfed, or breastfed for a shorter duration, (OR $0.84, p=0.02)$. This association was subject to marked heterogeneity $\left(I^{2}=61, p=0.001\right)$ - perhaps due in part to the different categorisations used in each study - and should therefore be carefully interpreted.

Table 3 shows the association between Caesarean section and type 1 diabetes after adjustment for confounders. The crude association between Caesarean section delivery and type 1 diabetes was little altered after adjustment for birthweight (OR 1.24, $p<0.001)$, gestational age (OR 1.19, $p<0.001$ ), maternal age (OR $1.19, p<0.001)$, birth order (OR 1.21, $p<0.001$ ), maternal diabetes (OR 1.17, $p=0.003$ ), breast-feeding (OR 1.26, $p<0.001)$ or all of these confounders (OR 1.19, $p=0.01)$.

\section{Discussion}

This meta-analysis demonstrates a consistent increase, of around $20 \%$, in the risk of type 1 diabetes in children delivered by Caesarean section. This observed increase in diabetes risk after Caesarean section delivery could not be explained by the confounding influence of birthweight, gestational age, maternal age, birth order, maternal diabetes or breastfeeding.

Table 2 Pooled analysis of the association between potential confounders and type 1 diabetes

\begin{tabular}{|c|c|c|c|c|c|c|}
\hline \multirow[t]{2}{*}{ Potential confounder } & \multirow[t]{2}{*}{ Number of studies } & \multicolumn{3}{|c|}{ Heterogeneity } & \multirow[t]{2}{*}{ Combined OR (95\% CI) } & \multirow[t]{2}{*}{$p$ value } \\
\hline & & $\chi^{2}$ & $p$ value & $I^{2}(95 \% \mathrm{CI})$ & & \\
\hline Birthweight (g) & 16 & & & & & \\
\hline$<2,500$ & & 21.05 & 0.14 & $29(0-61)$ & $0.87(0.71-1.07)$ & 0.18 \\
\hline $2,500-2,999$ & & 11.15 & 0.74 & $0(0-52)$ & $0.93(0.86-1.02)$ & 0.14 \\
\hline $3,000-3,499$ & & & & & 1.00 (Ref. cat.) & - \\
\hline $3,500-3,999$ & & 10.77 & 0.77 & $0(0-52)$ & $1.03(0.97-1.10)$ & 0.33 \\
\hline$\geq 4,000$ & & 11.24 & 0.74 & $0(0-52)$ & $1.12(1.02-1.21)$ & 0.01 \\
\hline Trend across categories & & 20.10 & 0.17 & $25(0-59)$ & $1.05(1.02-1.09)$ & 0.006 \\
\hline Gestational age (weeks) & 16 & & & & & \\
\hline$\leq 37$ & & 8.56 & 0.86 & $0(0-54)$ & $1.01(0.91-1.11)$ & 0.87 \\
\hline $38-41$ & & & & & 1.00 (Ref. cat.) & - \\
\hline$\geq 42$ & & 16.67 & 0.34 & $10(0-47)$ & $0.84(0.73-0.97)$ & 0.02 \\
\hline Maternal age (years) & 17 & & & & & \\
\hline$<20$ & & 29.54 & 0.02 & $46(4-69)$ & $0.84(0.68-1.04)$ & 0.10 \\
\hline $20-24$ & & 19.11 & 0.26 & $16(0-52)$ & $0.90(0.83-0.98)$ & 0.01 \\
\hline $25-29$ & & & & & 1.00 (Ref. cat.) & - \\
\hline $30-34$ & & 17.94 & 0.32 & $11(0-48)$ & $1.03(0.95-1.13)$ & 0.47 \\
\hline$\geq 35$ & & 14.01 & 0.59 & $0(0-51)$ & $1.11(1.01-1.23)$ & 0.04 \\
\hline Trend across categories & & 32.22 & 0.01 & $50(13-72)$ & $1.08(1.03-1.13)$ & 0.001 \\
\hline Birth order & 16 & & & & & \\
\hline First born & & & & & 1.00 (Ref. cat.) & - \\
\hline Second born & & 27.29 & 0.03 & $45(1-69)$ & $1.12(1.02-1.24)$ & 0.03 \\
\hline Third or later born & & 20.05 & 0.17 & $25(0-59)$ & $1.08(0.97-1.19)$ & 0.17 \\
\hline \multicolumn{7}{|l|}{ Maternal diabetes $^{\mathrm{a}}$} \\
\hline No & 8 & & & & 1.00 (Ref. cat.) & - \\
\hline Yes & & 6.42 & 0.49 & $0(0-68)$ & $4.92(3.93-6.16)$ & $<0.001$ \\
\hline \multicolumn{7}{|l|}{ Maternal type 1 diabetes ${ }^{\mathrm{a}}$} \\
\hline No & 8 & & & & 1.00 (Ref. cat.) & - \\
\hline Yes & & 3.05 & 0.88 & $0(0-68)$ & $4.03(1.76-9.20)$ & 0.001 \\
\hline \multicolumn{7}{|l|}{ Breast-feeding ${ }^{\mathrm{b}}$} \\
\hline No or short period & 15 & & & & 1.00 (Ref. cat.) & - \\
\hline Yes or long period & & 36.25 & 0.001 & $61(32-78)$ & $0.84(0.72-0.98)$ & 0.02 \\
\hline
\end{tabular}

${ }^{\text {a }}$ Studies recording maternal diabetes and maternal type 1 diabetes are shown in Table 1

${ }^{\mathrm{b}}$ Breast-feeding was categorised as breast-feeding at discharge from hospital [18, 32], any breast-feeding [15, 25, 27], breast-feeding for approximately 3 months or more [30, 40, 43] and breast-feeding for approximately 4 months or more [37-39]

Ref. cat., reference category 
The main finding was observed consistently across studies, conferring a level of robustness to this result. Importantly, using individual patient data, or adjusted estimates, we were able to demonstrate that the increased risk of diabetes after Caesarean section delivery could not be explained by known confounding factors. However, as this meta-analysis was based upon observational studies, it is impossible to rule out the influence of unrecorded confounders, although any such confounder would have to operate similarly across all studies. Social class is a possibility, as it may be associated with the likelihood of delivery by Caesarean section, but as the association between social class and type 1 diabetes is inconsistent $[24,44-46]$ it seems unlikely that it could exert the necessary confounding influence. Gestational diabetes is another possibility, but the proportion of mothers with gestational diabetes in these European populations is likely to be small [47], reducing the likelihood of marked confounding, and adjustment for gestational diabetes in seven of the studies $[15,25,27]$ revealed little evidence of confounding. A further weakness of this study was that the reason for Caesarean section could not be investigated, as this was not available in the majority of studies, and therefore we were unable to confirm a report suggesting that any increased risk of type 1 diabetes after Caesarean section was most marked after elective procedures [24].

The explanation for the observed increase in the risk of type 1 diabetes in children born by Caesarean section is unknown, but various theories are plausible. The gut microbiota are thought to play an important role in stimulating the development of the immune system [48]. Recent studies have shown that the gut microbiotic composition differ in children born by Caesarean section compared with vaginally born children [8-11], perhaps because such children are first exposed postpartum to bacteria originating from the hospital environment rather than to maternal bacteria [11]. This difference in gut microbiotic composition could increase the risk of type 1 diabetes. Similarly, the hygiene hypothesis suggests that children with reduced or delayed exposure to infection in early life may have an increased risk of type 1 diabetes [49]. According to this hypothesis, as children born by Caesarean section may have a reduced exposure to infections compared with children born vaginally, this could increase their diabetes risk. Alternatively, a previous study [42] speculated that any increased risk of diabetes after Caesarean section could be caused by nonspecific perinatal stress.

Our study also allowed the documentation of pooled estimates of the crude risk associated with various perinatal factors. Although not the result of a systematic review of the literature for each perinatal factor, there is no obvious reason why this selection of studies would not be representative. To our knowledge, this is the largest selection of studies that have been combined to investigate associations with birthweight, gestational age, maternal age, birth order and maternal diabetes. These analyses indicated that children who are heavier at birth, have a shorter gestation and whose mother has diabetes have a greater risk of type 1 diabetes. Although there was also evidence of an increased risk of type 1 diabetes with greater maternal age and later birth order, these associations varied considerably between studies and should be interpreted more cautiously. The findings for breast-feeding, of a slight reduction in type 1 diabetes risk, although broadly similar to that observed in two previous meta-analyses [50, 51], were subject to considerable heterogeneity, perhaps reflecting differences in the recording of breast-feeding in the individual studies.

Table 3 Pooled analysis of the association between Caesarean section and type 1 diabetes after adjustment for various potential confounders

\begin{tabular}{|c|c|c|c|c|c|c|c|}
\hline \multirow[t]{2}{*}{ Adjusted potential confounder(s) ${ }^{\mathrm{a}}$} & \multirow[t]{2}{*}{ No. of studies } & \multirow[t]{2}{*}{ No. of cases } & \multicolumn{3}{|c|}{ Heterogeneity } & \multirow{2}{*}{$\begin{array}{l}\text { Adjusted combined OR } \\
(95 \% \mathrm{CI})\end{array}$} & \multirow[t]{2}{*}{$p$ value } \\
\hline & & & $\chi^{2}$ & $p$ value & $I^{2}(95 \% \mathrm{CI})$ & & \\
\hline None & 20 & 9,938 & 17.70 & 0.54 & $0(0-48)$ & $1.23(1.15-1.32)$ & $<0.001$ \\
\hline Birthweight & 16 & 6,138 & 13.55 & 0.56 & $0(0-52)$ & $1.24(1.13-1.35)$ & $<0.001$ \\
\hline Gestational age & 16 & 6,005 & 14.10 & 0.52 & $0(0-52)$ & $1.19(1.09-1.31)$ & $<0.001$ \\
\hline Maternal age & 17 & 6,246 & 16.04 & 0.45 & $0(0-51)$ & $1.19(1.09-1.30)$ & $<0.001$ \\
\hline Birth order & 16 & 6,029 & 16.19 & 0.37 & $7(0-43)$ & $1.21(1.10-1.34)$ & $<0.001$ \\
\hline Maternal diabetes & 16 & 6,150 & 16.79 & 0.33 & $11(0-48)$ & $1.17(1.05-1.29)$ & 0.003 \\
\hline Breastfeeding & 15 & 3,874 & 9.00 & 0.83 & $0(0-54)$ & $1.26(1.12-1.42)$ & $<0.001$ \\
\hline $\begin{array}{l}\text { Birthweight, gestational age, } \\
\text { maternal age and birth order }\end{array}$ & 15 & 5,791 & 11.30 & 0.66 & $0(0-54)$ & $1.17(1.06-1.28)$ & 0.001 \\
\hline $\begin{array}{l}\text { Birthweight, gestational age, } \\
\text { maternal age, birth order and breastfeeding }\end{array}$ & 13 & 3,444 & 7.86 & 0.80 & $0(0-57)$ & $1.21(1.06-1.38)$ & 0.005 \\
\hline $\begin{array}{l}\text { Birthweight, gestational age, maternal age, } \\
\text { birth order, breastfeeding and maternal diabetes }\end{array}$ & 13 & 3,424 & 9.16 & 0.69 & $0(0-57)$ & $1.19(1.04-1.36)$ & 0.01 \\
\hline
\end{tabular}

\footnotetext{
${ }^{a}$ Adjustments were made for potential confounders using broadly the categories shown in Table 2
} 
In conclusion, our study detected a small but significant and consistent increase in the risk of type 1 diabetes after Caesarean section, which could reflect differences in exposure to bacteria in early life.

Acknowledgements The authors acknowledge support from the following: the Czech Republic Ministry of Education (grant MSM 0021620814), the NHS National Coordinating Centre for Research Capacity Development UK, the Research Council of Norway, Diabetes UK and the Northern Ireland Department of Health and Social Services. Finally, thanks are also due to G. Soltész and G. Dahlquist, EURODIAB Substudy 2 co-ordinators

Duality of Interest The authors declare that there is no duality of interest associated with this manuscript.

\section{References}

1. Field LL (2002) Genetic linkage and association studies of type I diabetes: challenges and rewards. Diabetologia 45:21-35

2. Green A, Patterson CC (2001) Trends in the incidence of childhood-onset diabetes in Europe 1989-1998. Diabetologia 44 (Suppl 3):B3-B8

3. Onkamo P, Vaananen S, Karvonen M, Tuomilehto J (1999) Worldwide increase in incidence of type I diabetes - the analysis of the data on published incidence trends. Diabetologia 42:1395-1403

4. Thomas J, Paranjothy S, Royal College of Obstetricians and Gynaecologists Clinical Effectiveness Support Unit (2007) National sentinel caesarean section audit report. RCOG Press, London

5. Notzon FC, Placek PJ, Taffel SM (1987) Comparisons of national Cesarean-section rates. N Engl J Med 316:386-389

6. Wilberz S, Partke HJ, Dagnaes-Hansen F, Herberg L (1991) Persistent MHV (mouse hepatitis virus) infection reduces the incidence of diabetes mellitus in non-obese diabetic mice. Diabetologia 34:2-5

7. Like AA, Guberski DL, Butler L (1991) Influence of environmental viral agents on frequency and tempo of diabetes mellitus in BB/Wor rats. Diabetes 40:259-262

8. Grönlund MM, Nuutila J, Pelto L et al (1999) Mode of delivery directs the phagocyte functions of infants for the first 6 months of life. Clin Exp Immunol 116:521-526

9. Grönlund MM, Lehtonen OP, Eerola E, Kero P (1999) Fecal microflora in healthy infants born by different methods of delivery: permanent changes in intestinal flora after Cesarean delivery. J Pediatr Gastroenterol Nutr 28:19-25

10. Salminen S, Gibson GR, McCartney AL, Isolauri E (2004) Influence of mode of delivery on gut microbiota composition in seven year old children. Gut 53:1388-1389

11. Penders J, Thijs C, Vink $C$ et al (2006) Factors influencing the composition of the intestinal microbiota in early infancy. Pediatrics 118:511-521

12. Blettner M, Sauerbrei W, Schlehofer B, Scheuchenpflug T, Friedenreich C (1999) Traditional reviews, meta-analyses and pooled analyses in epidemiology. Int J Epidemiol 28:1-9

13. Stene LC, Magnus P, Lie RT, Søvik O, Joner G, The Norwegian Childhood Diabetes Study Group (2001) Maternal and paternal age at delivery, birth order, and risk of childhood onset type 1 diabetes: population based cohort study. BMJ 323:369

14. Sadauskaite-Kuehne V, Ludvigsson J, Padaiga Z, Jašinskienè E, Samuelsson U (2004) Longer breastfeeding is an independent protective factor against development of type 1 diabetes mellitus in childhood. Diabetes Metab Res Rev 20:150-157
15. Dahlquist G, Patterson C, Soltész G (1999) Perinatal risk factors for childhood type 1 diabetes in Europe. The EURODIAB Substudy 2 Study Group. Diabetes Care 22:1698-1702

16. Kirkwood BR, Sterne JAC (2003) Essential medical statistics. Blackwell Science, Oxford, p 243

17. Stene LC, Magnus P, Lie RT, Søvik O, Joner G, The Norwegian Childhood Diabetes Study Group (2003) No association between preeclampsia or Cesarean section and incidence of type 1 diabetes among children: a large, population-based cohort study. Pediatr Res 54:487-490

18. Ievins R, Roberts SE, Goldacre MJ (2007) Perinatal factors associated with subsequent diabetes mellitus in the child: record linkage study. Diabet Med 24:664-670

19. Dersimonian R, Laird N (1986) Meta-analysis in clinical-trials. Controlled Clinical Trials 7:177-188

20. Higgins JP, Thompson SG, Deeks JJ, Altman DG (2003) Measuring inconsistency in meta-analyses. Br Med J 327:557-560

21. Sterne JAC, Egger M (2001) Funnel plots for detecting bias in meta-analysis: guidelines on choice of axis. J Clin Epidemiol 54:1046-1055

22. Stukel TA, Demidenko E, Dykes J, Karagas MR (2001) Twostage methods for the analysis of pooled data. Stat Med 20:21152130

23. Duval S, Tweedie R (2000) Trim and fill: a simple funnelplot-based method of testing and adjusting for publication bias in meta-analysis. Biometrics 56:455-463

24. Patterson CC, Carson DJ, Hadden DR, Waugh NR, Cole SK (1994) A case-control investigation of perinatal risk factors for childhood IDDM in Northern Ireland and Scotland. Diabetes Care 17:376-381

25. McKinney PA, Parslow R, Gurney K, Law G, Bodansky HJ, Williams DR (1997) Antenatal risk factors for childhood diabetes mellitus; a case-control study of medical record data in Yorkshire, UK. Diabetologia 40:933-939

26. McKinney PA, Parslow R, Gurney KA, Law GR, Bodansky HJ, Williams R (1999) Perinatal and neonatal determinants of childhood type 1 diabetes. A case-control study in Yorkshire, U. K. Diabetes Care 22:928-932

27. Rami B, Schneider U, Imhof A, Waldhor T, Schober E (1999) Risk factors for type I diabetes mellitus in children in Austria. Eur J Pediatr 158:362-366

28. McKinney PA, Okasha M, Parslow RC et al (2000) Early social mixing and childhood type 1 diabetes mellitus: a case-control study in Yorkshire, UK. Diabet Med 17:236-242

29. Stene LC, Barriga K, Norris JM et al (2004) Perinatal factors and development of islet autoimmunity in early childhood: the diabetes autoimmunity study in the young. Am J Epidemiol 160:3-10

30. Stene LC, Joner G, The Norwegian Childhood Diabetes Study Group (2004) Atopic disorders and risk of childhood-onset type 1 diabetes in individuals. Clin Exp Allergy 34:201-206

31. Visalli N, Sebastiani L, Adorisio E et al (2000) Caesarean section delivery and vitamin D supplement: risk and protective factors for type 1 diabetes. Diabetologia 43(Suppl 1):369 (Abstract)

32. Cardwell CR, Carson DJ, Patterson CC (2005) Parental age at delivery, birth order, birth weight and gestational age are associated with the risk of childhood type 1 diabetes: a UK regional retrospective cohort study. Diabet Med 22:200-206

33. Soltész G, Jeges S, Dahlquist G et al (1994) Nongenetic risk determinants for type-I (insulin-dependent) diabetes-mellitus in childhood. Acta Paediatr 83:730-735

34. Tai TY, Wang CY, Lin LL, Lee LT, Tsai ST, Chen CJ (1998) A case-control study on risk factors for type 1 diabetes in Taipei City. Diabetes Res Clin Pract 42:197-203

35. Jones ME, Swerdlow AJ, Gill LE, Goldacre MJ (1998) Pre-natal and early life risk factors for childhood onset diabetes mellitus: a record linkage study. Int J Epidemiol 27:444-449 
36. Bache I, Bock T, Volund A, Buschard K (1999) Previous maternal abortion, longer gestation, and younger maternal age decrease the risk of type 1 diabetes among male offspring. Diabetes Care 22:1063-1065

37. Svensson J, Carstensen B, Mortensen HB, Borch-Johnsen K (2005) Early childhood risk factors associated with type 1 diabetes-is gender important? Eur J Epidemiol 20:429-434

38. Šipetić SB, Vlajinac HD, Kocev NI, Marinković JM, Radmanović SZ, Bjekić MD (2005) The Belgrade childhood diabetes study: a multivariate analysis of risk determinants for diabetes. Eur $\mathbf{J}$ Public Health 15:117-122

39. Malcova H, Sumnik Z, Drevinek P, Venhacova J, Lebl J, Cinek O (2006) Absence of breast-feeding is associated with the risk of type 1 diabetes: a case-control study in a population with rapidly increasing incidence. Eur J Pediatr 165:114-119

40. Tenconi MT, Devoti G, Comelli M et al (2007) Major childhood infectious diseases and other determinants associated with type 1 diabetes: a case-control study. Acta Diabetol 44:14-19

41. Blom L, Dahlquist G, Nyström L, Sandström A, Wall S (1989) The Swedish childhood diabetes study-social and perinatal determinants for diabetes in childhood. Diabetologia 32:7-13

42. Dahlquist G, Källén B (1992) Maternal-child blood group incompatibility and other perinatal events increase the risk for early-onset type 1 (insulin-dependent) diabetes mellitus. Diabetologia 35:671-675
43. Visalli N, Sebastiani L, Adorisio E et al (2003) Environmental risk factors for type 1 diabetes in Rome and province. Arch Dis Child 88:695-698

44. Wadsworth EJK, Shield JPH, Hunt LP, Baum JD (1997) A casecontrol study of environmental factors associated with diabetes in the under 5s. Diabet Med 14:390-396

45. Cardwell CR, Carson DJ, Patterson CC (2007) Secular trends, disease mapping and ecological analyses of the incidence of childhood onset type 1 diabetes in Northern Ireland, 1989-2003. Diabet Med 24:289-95

46. du Prel JB, Icks A, Grabert M, Holl RW, Giani G, Rosenbauer J (2007) Socioeconomic conditions and type 1 diabetes in childhood in North Rhine-Westphalia, Germany. Diabetologia 50:720 728

47. Hunt KJ, Schuller KL (2007) The increasing prevalence of diabetes in pregnancy. Obstet Gynecol Clin North Am 34:173-199

48. Guarner F, Malagelada JR (2003) Gut flora in health and disease. Lancet 361:512-519

49. Gale EA (2002) A missing link in the hygiene hypothesis? Diabetologia 45:588-594

50. Norris JM, Scott FW (1996) A meta-analysis of infant diet and insulin-dependent diabetes mellitus: do biases play a role? Epidemiology 7:87-92

51. Gerstein HC (1994) Cow's milk exposure and type I diabetes mellitus. A critical overview of the clinical literature. Diabetes Care 17:13-19 